\title{
Hawk-Moths of Great Britain and Europe, by L. Hugh Newman. Cassell, 50s.
}

This fascinating book, by a well-known naturalist, writer and broadcaster, deals with some of the largest and most beautiful moths to be found in this country and Europe. The group of twenty-three species is divided into three categories; nine resident in Great Britain, nine which migrate here more or less frequently from the Continent, and five found only in Europe. Mr. Newman deals with the life history of each species from the egg to the perfect insect, giving details of the food of the caterpillars and of the appearance, variations, habits and general behaviour in all stages, enriched by many personal experiences from his thinty-five years of running his butterfly and moth farm in Kent. His observations are interesting and accurate, and of great value to any would-be breeder of the hawkmoth.

At fifty shillings the book may seem rather expensive, but it is beautifully printed and produced, and very lavishly illustrated. There are forty pages of photographs, including many of living insects in their natural surnoundings; twenty-four are in colour, most of them are excellent and some superb; only in a few instances are the colours a little disappointing. There is an enthusiastic foreword by Peter Scott, and an adequate index. It would be hard to imagine a more admirable and useful present for a keen young lepidopterist.

\section{R. SAUNDBY.}

\section{Charles Darwin and his World, by Julian Huxley and H. B. D. Kettlewell. Thames \& Hudson, 25s.}

In this slim volume of 144 pages, less than half the space is allotted to the script, the rest to the admirably chosen illustrations. Yet the presentation is so brilliantly carried out that the story of Darwin the man, and the impact of his work on 19th century thought is told once again without the staleness of a dished-up theme. The book is divided into three sections, The Prelude, 1809-1831, The Experience, 1831-1836, The Synthesis, 1836-1882. The impontance of the Beagle Voyage-The Experience-is stressed as the intellectual basis, whilst the portrait of Darwin in his family and as an intimate friend is sympathetically brought to life throughout. The authors write in their Introduction:- "Only by studying Charles Darwin in the three phases of his life can we come to understand the man who contributed so much to science, to religious and philosophical discussion and to the concepts of Man and his destiny". The reader with little preknowledge of the subject will surely be fired to further reading. On the much debated question of Darwin's ill-health, the authors steer a safe course between the neurological or psychological Scylla, and the Chagus Charybdis as possible causative agents, and point out that the two are not necessarily incompatible.

Inaccuracies have been overlooked which it is hoped may be corrected in future editions. The statements about Erasmus Darwin's scientific works are wrong and misleading; Charles was plagued with sea-sickness to the end of the voyage; he called himself an agnostic, not an atheist. In a footnote to the Introduction to Animals and Plants under Domestication it should be noted that Charles states that this is the promised long-delayed work incorporating the facts on which the conclusions of $O n$ the Origin of Species were founded. In the reviewer's opinion, the authors follow the stereotyped view of Robert as far too severe and inflexible a heavy father.

In further editions could there not be both a bibliography and a fuller index?

NORA BARLOW. 